Research Paper

\title{
Effect of Liposomal Doxorubicin in Pressurized Intra-Peritoneal Aerosol Chemotherapy (PIPAC)
}

\author{
Agata Mikolajczyk1, Veria Khosrawipour², Justyna Schubert ${ }^{3}$, Jakub Grzesiak 4, Haris Chaudhry5, Alessio \\ Pigazzi 5, Tanja Khosrawipour 5,6 \\ 1. Department of Biochemistry and Molecular Biology, Faculty of Veterinary Medicine, Wroclaw University of Environmental and Life Sciences, Wroclaw, \\ Poland \\ 2. Department of Orthopedic and Trauma Surgery, Ortho-Klinik Dortmund, Dortmund, Germany \\ 3. Department of Food Hygiene and Consumer Health Protection, Wroclaw University of Environmental and Life Sciences, Wroclaw, Poland \\ 4. Electron Microscopy Laboratory, Wroclaw Research Centre EIT+, Wroclaw, Poland \\ 5. Division of Colorectal Surgery, Department of Surgery, University of California Irvine (UCI), California, USA \\ 6. Department of Surgery (A), Heinrich-Heine-University and University Hospital Duesseldorf, Duesseldorf, Germany
}

$\triangle$ Corresponding author: Tanja Khosrawipour, MD, Division of Colorectal Surgery, Department of Surgery, University of California Irvine (UCI), California, USA. Tel: + 001(714)456-5443; Email: tkhosrawipour@gmail.com

(1) Ivyspring International Publisher. This is an open access article distributed under the terms of the Creative Commons Attribution (CC BY-NC) license (https://creativecommons.org/licenses/by-nc/4.0/). See http://ivyspring.com/terms for full terms and conditions.

Received: 2018.04.24; Accepted: 2018.09.07; Published: 2018.10.20

\begin{abstract}
Background: This ex-vivo study was performed to compare the impact of doxorubicin vs. liposomal doxorubicin on penetration depth in peritoneal tissue during Pressurized Intra-Peritoneal Aerosol Chemotherapy (PIPAC) via microcatheter (MC).

Methods: Fresh post mortem swine peritoneum was cut into proportional sections. One group of samples was treated with PIPAC with Doxorubicin (D), and the other was treated with PIPAC with liposomal doxorubicin (LD). Tissue specimens were placed as follows: at the bottom of the plastic box (1), at the side wall (2), at the top cover (3) and the side of the box covered by a plastic tunnel (4). In-tissue doxorubicin penetration was measured using fluorescence microscopy on frozen thin sections.

Results: Medium penetration levels with D were $325 \mu \mathrm{m}$ (1), $152 \mu \mathrm{m}$ (2), $84 \mu \mathrm{m}$ (3) and $71 \mu \mathrm{m}$ (4), respectively. Medium penetration levels with LD were significantly lower with $10 \mu \mathrm{m}(1), 2 \mu \mathrm{m}(2)$, $0 \mu \mathrm{m}(3)$ and $0 \mu \mathrm{m}$ (4), respectively. In most samples that were treated with LD no doxorubicin could be detected at all.

Conclusion: Our data indicate that liposomal coating of doxorubicin and possibly other chemotherapeutical drugs might inhibit their interaction with the peritoneal surface. This inhibition appears to be relatively strong, since doxorubicin is partially undetectable due to liposomal coating. Further studies are warranted to investigate this interaction and its potential benefit in peritoneal applications.
\end{abstract}

Key words: $e x$-vivo, drug penetration, Pressurized Intra-Peritoneal Aerosol Chemotherapy (PIPAC), peritoneal carcinomatosis, liposomal doxorubicin

\section{Introduction}

Pressurized Intraperitoneal Aerosol Chemotherapy (PIPAC) has been introduced as an innovative approach to improve the treatment of advanced peritoneal metastasis (PM). The drug containing solution is delivered into the abdominal cavity in the shape of microparticles using an aerosol-producing device $[1,2]$. Penetration depth of PIPAC has been reported to be up to $600 \mu \mathrm{m}[3,4]$ with tissue concentrations ranging from 0.03 to $4.1 \mu \mathrm{mol} / \mathrm{g}$ [1]. Despite improvements in PIPAC treatment, the overall outcome of patients with PM remains poor. Alternative drug compositions and therapeutic particles are currently being studied for the treatment of PM [5, 6]. 
To date, there has been no investigation in the performance and behavior of new complex particles during PIPAC. Complex particles might enhance or reduce the overall anti-tumoral effect on PM due to altered interaction with the peritoneal surface. Theoretically, encapsulated doxorubicin in the form of liposomal doxorubicin (LD) might have an increased tissue penetration effect when applied as a pressurized intraperitoneal aerosol with higher cytotoxicity and increased penetration in PIPAC. A Phase I trial by Harrison et al. of LD in cytoreductive surgery and HIPEC showed that LD is well tolerated with encouraging survival rates [7]. Our study is the first to analyze the behavior of a complex heterogeneous particle with regard to its effect following the transformation into an aerosol and its interaction with the peritoneum. The main focus of this study is to investigate penetration and interaction of the LD with the peritoneum by measuring the in-depth tissue penetration of doxorubicin using fluorescent microscopy. Second, this study aims to evaluate the effect of the LD aerosol at different positions within the box model mimicking the abdominal cavity in order to assess whether LD aerosol particles have different physical distribution properties. These could influence local drug availability. To compare the impact of LD, PIPAC was also performed with doxorubicin using the same ex-vivo model.

\section{Material \& Methods}

\section{Ex-vivo PIPAC model}

Since the experiments were performed in an ex-vivo model on commercially available tissue samples, no approval of the Local Board on Animal Care was required. Fresh post mortem swine peritoneum was cut into 12 proportional sections. Two groups were established: In group A samples received PIPAC with doxorubicin (Doxorubicin hydrochloride was purchased from PFS®, $2 \mathrm{mg} / \mathrm{ml}$, Pfizer Europe, Sandwich, United Kingdom) while in group B samples received PIPAC with LD (Caelyx ${ }^{\circledR}$, European trademark of Doxil ${ }^{\circledR}$, Janssen-Cilag, BHZ0V00). The ex-vivo PIPAC model has previously been described [8-10]. A commercially available hermetic sealable plastic box with a total volume of 3.5 liter, representing the abdominal cavity, was used. In the center of the top cover of the plastic box, a $5 \mathrm{~mm}$ trocar (Kii®Balloon Blunt Tip System, Applied Medical, Rancho Santa Margarita, CA, USA) was placed. The nozzle of the microcatheter (MC, Olympus, PW-205V Olympus Surgical Technologies Europe, Hamburg, Germany) was introduced into the trocar. The plastic box was kept at a constant room temperature of $27^{\circ}$ degrees Celsius during the whole procedure. Fresh tissue specimen of peritoneum (German land race pigs), each measuring $4.0 \times 4.0 \times$ $0.5 \mathrm{~cm}$, were placed at different locations of the plastic box: (1) bottom of the plastic box, (2) side wall, (3) top cover, and at the (4) margin of the aerosol jet covered with a bilaterally open tunnel (Figure 1). The distance between the nozzle of the MC and the bottom of the plastic box was $10 \mathrm{~cm}$. The plastic box was then tightly sealed and a constant $\mathrm{CO}_{2}$ capnoperitoneum of 12 mmHg (Olympus UHI-3, Olympus medical life science and industrial divisions, Olympus Australia, Notting Hill, Australia) was maintained during the entire PIPAC procedure. $3 \mathrm{mg}$ of doxorubicin in Experiment $\mathrm{A}$ and $3 \mathrm{mg}$ of $\mathrm{LD}$ in experiment $\mathrm{B}$ were dissolved in $50 \mathrm{ml} \mathrm{NaCl} 0.9 \%$ at room temperature $\left(27^{\circ} \mathrm{C}\right)$. The solution was then aerosolized at a speed of $1 \mathrm{ml} / \mathrm{sec}$ using high manual pressure on a $10 \mathrm{ml}$ syringe. After the aerosol phase, the tissue specimens were exposed to another 30 minutes of aerosolized doxorubicin (exposure phase).

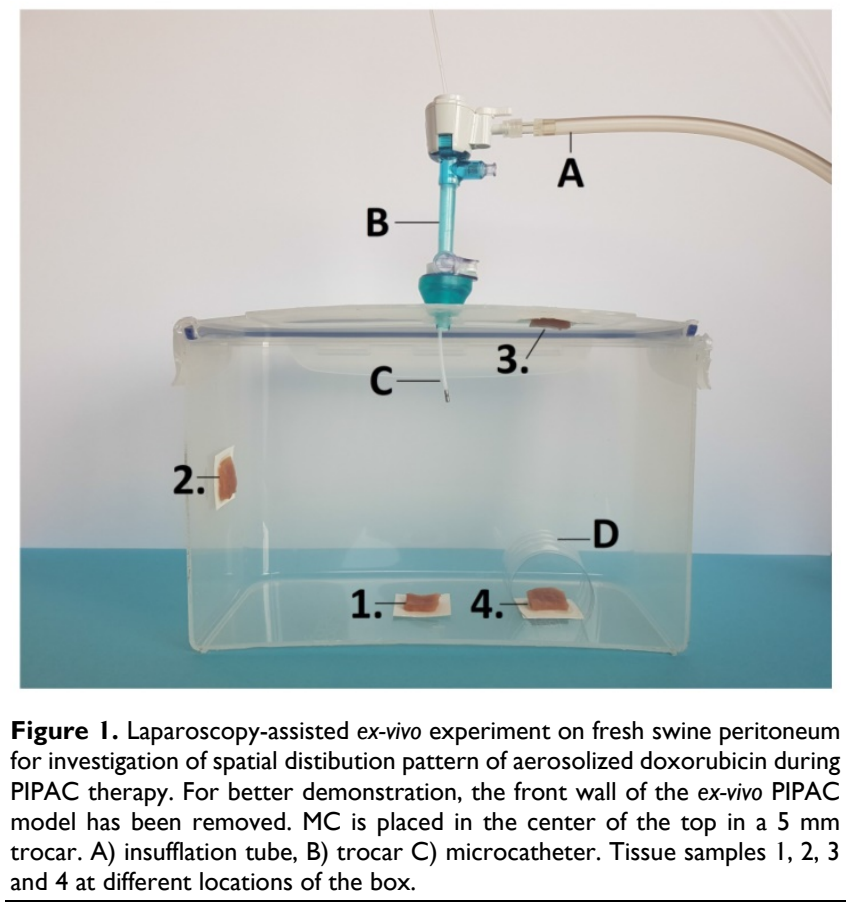

\section{Microscopic analysis}

After treatments, all tissue samples were rinsed with sterile $\mathrm{NaCl} 0.9 \%$ solution in order to eliminate superficial cytostatics and immediately frozen in liquid nitrogen. Cryo sections $(10 \mu \mathrm{m})$ were prepared from different areas of each specimen. Sections were mounted with VectaShield containing $1.5 \mu \mathrm{g} / \mathrm{ml}$ 4',6-diamidino-2-phenylindole (DAPI) to stain nuclei. Penetration depth of doxorubicin was monitored using Nikon Eclipse 80i fluorescence microscope 
(Nikon Instruments Europe B.V. Amsterdam, Netherlands). The distance between the luminal surface and the innermost positive staining for doxorubicin accumulation was measured and reported in micrometers.

\section{LD detection via electron microscopy (EM)}

The surface of a representative amount of the peritoneal tissue sample treated with LD was analyzed and visualized via cryogenic scanning electron microscopy (cryo-SEM) Figure 4. Tissue was fixed overnight in $2.5 \%$ glutaraldehyde solution in phosphate buffer $(\mathrm{pH}=7.2)$. After fixation, sample was washed in phosphate buffer, rinsed in ultrapure (filtered through $0.1 \mu \mathrm{m}$ syringe filter) deionized water, mounted on cryo shuttle using OCT/ colloidgraphite mixture and plunged in liquid nitrogen. The frozen specimen was then quickly transferred to cryo-preparation chamber (Cryo Quorum PP3010T) and sputtered with conductive layer of platinum at $-140^{\circ} \mathrm{C}$, followed by its transfer to the microscope chamber maintaining same temperature $-140^{\circ} \mathrm{C}$ (Auriga 60, Zeiss). Sample was observed at $2 \mathrm{kV}$ of acceleration voltage using In Lens and SE2 secondary electron detectors.

\section{Statistical analyses}

Experiments were independently performed three times. A total of eight tissue sections per tissue sample were subject to doxorubicin penetration measurement. The statistical analyses were performed via Sigma Plot 12 (Systat Software Inc., California, USA). The Kruskal-Wallis One Way Analysis of Variance on Ranks was used for analyses of independent groups. A significant $p$-value was considered at $\mathrm{p}<0.01$.

\section{Results}

\section{Ex-Vivo experiment}

Penetration of Doxorubicin after PIPAC was 325 $\pm 51 \mu \mathrm{m}$ at the bottom of the plastic box (1), $152 \pm 54$ $\mu \mathrm{m}$ at the side wall (2), $81 \pm 38 \mu \mathrm{m}$ at the top cover (3) and $71 \mu \mathrm{m} \pm 37$ at the covered bottom (4) of the box. Penetration of LD after PIPAC was $10 \pm 12 \mu \mathrm{m}$ at the bottom of the plastic box (1), $2 \pm 4 \mu \mathrm{m}$ at the side wall (2), and not detectable at the top cover (3) or the covered bottom (4) of the box. Very little if any doxorubicin was detected in tissues of experiment $B$ in contrast to experiment A. In LD samples that were not in close range to the direct sprayjet, no doxorubicin was detected in the tissue. Distribution pattern of doxorubicin in PIPAC was similar to previous experiments [9]. No distribution pattern could be established for LD due to low tissue penetration levels. Accordingly, penetration differences were highly significant when comparing PIPAC with doxorubicin and LD.

\section{EM of peritoneal tissue}

The applied magnification was 36800x. LD was detected on the peritoneal surface via cryo-SEM (Figure 4). Most particles had a round spherical form. The medium size of particles was at $71 \pm 14 \mathrm{~nm}$. Some of the particles accumulated to larger droplets. These were around $0.5 \mu \mathrm{m}$ to up about $5 \mu \mathrm{m}$ in diameter. Many stable, undissolved particles and their aggregates could be detected in close contact with the peritoneum.

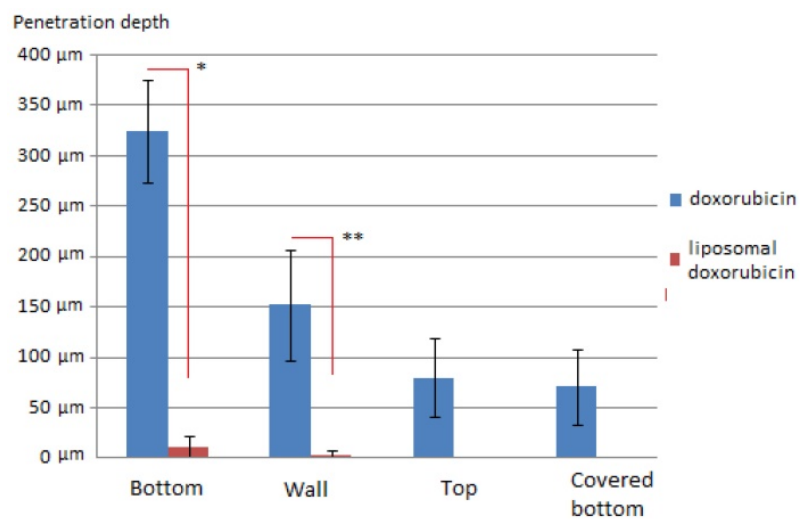

Figure 2. Tissue penetration depth of doxorubicin (blue) and liposomal doxorubicin (red) in $\mu \mathrm{m}$ in PIPAC $* \mathrm{p}<0.0000001 * * \mathrm{p}<0.00001$

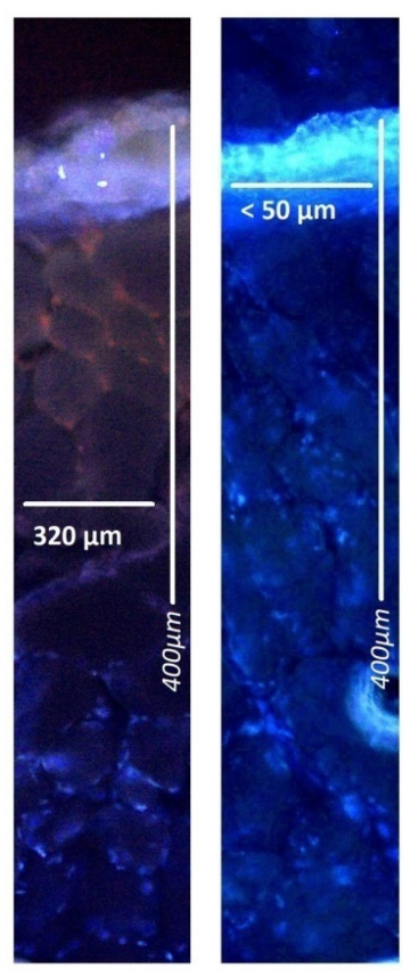

Figure 3. Microscopic analysis of maximum and minimum penetration depth of doxorubicin into fresh peritoneal tissue samples of German land race pigs. Nuclei (blue) were stained with 4',6-diamidino-2-phenylindole (DAPI). Left side to right: doxorubicin versus liposomal doxorubicin 


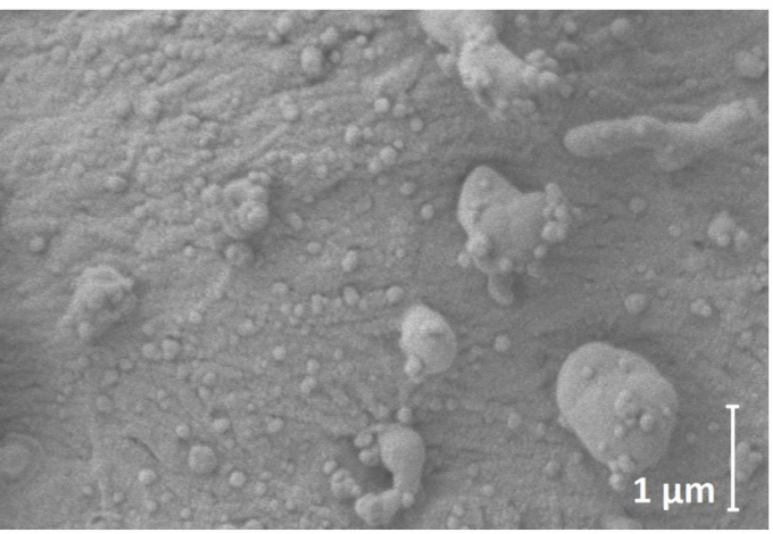

Figure 4. Cryogenic scanning electron microscopy of peritoneal surface after PIPAC with LD $(3 \mathrm{mg} / 50 \mathrm{ml})$; magnification level 36800

\section{Discussion}

In spite of progress in chemotherapeutic regimens and new drug compositions, poor response to systemic and local treatment is observed in a considerable part of patients, mainly due to molecular mechanisms and limited drug distribution in the tumor [11-14]. PIPAC is a novel approach that promises a valuable treatment option for patients who do not qualify for Cytoreductive surgery and HIPEC. PIPAC therapy has been introduced as a new and innovative approach to improve the treatment of advanced, multi-resistant PM. Data obtained in animal experiments describe a high level of peritoneal tissue penetration rates of applied chemotherapeutic drugs via PIPAC [15-17]. Recent findings demonstrate promising results concerning clinical benefits [18] and histological efficacy on PM [19]. Several authors have reported that increasing tissue penetration enhances the anti-tumoral effect with higher local drug disposition [20, 21]. Performing PIPAC with LD might increase its overall efficacy by means of improving penetration into the tissue. This has been indicated by previously analyzing the effect of LD on HIPEC [6]. Theoretically, LD is assumed to have a higher penetrating effect and leads to higher cytotoxicity after PIPAC, provided how LD interacts with the peritoneal tissue after PIPAC. This interaction seems to be much more complex than anticipated. Studies with different liposomal particles in the peritoneal cavity have indicated that the use of a liposome carrier alters the systemic absorption and tissue distribution in IP therapeutics [22-24]. In our experiment, LD itself does not seem to easily interact with the peritoneal surface unless doxorubicin is released by other means. The reduced penetration of LD as observed in this study may probably be even more complicated by the inability of PIPAC to disrupt the LD structure by mechanical means, preventing the release of encoated doxorubicin. While this study is the first of its kind and gives an important insight into the differences of penetration depth when comparing liposomal vs. conventional doxorubicin in PIPAC, some limiting factors need to be considered. This study uses an ex-vivo box model mimicking the peritoneal cavity. Thus, non-vascularized tissue may have different absorbent properties than peritoneum in an in-vivo model.

In future, the characteristics of LD can be used to create an intraperitoneal LD reservoir from which doxorubicin could be released by other means. It has been determined that these particles are better tolerated and show higher maximal tolerated doses compared to free drug solutions due to slower drug release [25, 26]. Drug release can then be mediated with time or enhanced by ultrasound, hyperthermia or other means as previously described [27, 28]. However, this could be complicated by the fact that intraperitoneal liposomal particles are in partial systemically absorbed. Findings indicate that liposomal particles that are not initially absorbed by the peritoneum will, after some time, be drained by the lymphatic ducts into systemic circulation [29] or finally absorbed at surgical resection sites following cytoreductive surgery [6].

More studies have to be considered since the interaction of complex particles with treated peritoneal tissue has not yet been fully analyzed and evaluated in PIPAC. Although the influence of physical properties in PIPAC has been studied [30], many effects and interactions of new substances are practically unknown. However, we believe that our findings show that application of complex micro and nanoparticles via PIPAC need to be more thoroughly studied before assuming any potential clinical effects. There is practically no data on the application and effect of complex micro and nanoparticles in PIPAC. Nevertheless, the described findings may demonstrate the need for further research in this field.

\section{Conclusions}

Our data indicate that LD practically does not penetrate the peritoneum and the release of in-tissue doxorubicin is inhibited by liposomal coating. Liposomal coating has a more complicated effect on the interaction with the peritoneum. These properties might also be used to possibly create a doxorubicin reservoir. For this purpose, it has to be warranted that the reservoir shows no leakage that may be caused by previous tissue resection during cytoreductive surgery or by absorption into lymphatic ducts. Mechanical, thermal and ultrasound-assisted release of doxorubicin might then be utilized for controlled penetration into metastatic tissue. Further studies are 
warranted to investigate the impact and therapeutic possibilities of LD on tumor cells during PIPAC application and to find out the best possible setting for chemoagent usage in peritoneal metastases.

\section{Abbreviations}

$\mathrm{CO}_{2}$, Carbon Dioxide; CRS, Cytoreductive Surgery; EM, Electron microscopy; HIPEC, Heated Intra-Peritoneal Chemotherapy; IAP, IntraAbdominal Pressure; IPC, Intra-Peritoneal Chemotherapy; LD, Liposomal doxorubicin; PM, Peritoneal metastasis; PCI, Sugarbaker's Peritoneal Cancer Index; PIPAC, Pressurized Intra-Peritoneal Aerosol Chemotherapy; MC, Microcatheter.

\section{Acknowledgements}

Mikolajczyk, Agata: Study design, laboratory analysis, data acquisition; Khosrawipour, Veria: Study design, laboratory analysis, data acquisition and manuscript drafting; Schubert, Justyna: Laboratory analysis and data acquisition; Grzesiak, Jakub: Laboratory analysis and data acquisition; Chaudhry, Haris: drafting and critical revision for important intellectual content of the manuscript; Pigazzi, Alessio: drafting and critical revision for important intellectual content of the manuscript; Khosrawipour, Tanja: Supervision of the study, drafting and critical revision for important intellectual content of the manuscript.

\section{Competing Interests}

The authors have declared that no competing interest exists.

\section{References}

[1] Solaß W, Kerb R, Muerdter T, et al. Intraperitoneal chemotherapy of peritoneal carcinomatosis using pressurized aerosol as an alternative to liquid solution: first evidence for efficacy. Ann Surg Oncol. 2014; 21:553-559.

[2] Göhler D, Khosrawipour V, Khosrawipour T, et al. Technical description of the microinjection pump (MIP®) and granulometric characterization of the aerosol applied for pressurized intraperitoneal aerosol chemotherapy (PIPAC). Surg Endosc. 2017; 31(4):1778-1784.

[3] Khosrawipour V, Giger-Pabst U, Khosrawipour T, et al. Effect of Irradiation on Tissue Penetration Depth of Doxorubicin after Pressurized Intra-Peritoneal Aerosol Chemotherapy (PIPAC) in a Novel Ex-Vivo Model. J Cancer. 2016; 7(8):910-914

[4] Khosrawipour V, Bellendorf A, Khosrawipour C, et al. Irradiation Does Not Increase the Penetration Depth of Doxorubicin in Normal Tissue After Pressurized Intra-peritoneal Aerosol Chemotherapy (PIPAC) in an Ex Vivo Model. In Vivo. 2016; 30(5):593-597.

[5] Solaß W, Herbette A, Schwarz T, et al. Therapeutic approach of human peritoneal carcinomatosis with Dbait in combination with capnoperitoneum: proof of concept. Surg Endosc. 2012; 26:847-852.

[6] Salvatorelli E, De Tursi M, Menna P, et al. Pharmacokinetics of pegylated liposomal doxorubicin administered by intraoperative hyperthermic intraperitoneal chemotherapy to patients with advanced ovarian cancer and peritoneal carcinomatosis. Drug MetabDispos. 2012; 40(12):2365-2373.

[7] Harrison LE, Bryan M, Pliner L, et al. Phase I trial of pegylated liposomal doxorubicin with hyperthermic intraperitoneal chemotherapy in patients undergoing cytoreduction for advanced intra-abdominal malignancy. Ann SurgOncol. 2008; 15(5):1407-1413.

[8] Khosrawipour V, Khosrawipour T, Falkenstein TA, et al. Evaluating the Effect of Micropump $\odot$ Position, Internal Pressure and Doxorubicin Dosage on Efficacy of Pressurized Intra-peritoneal Aerosol Chemotherapy (PIPAC) in an Ex Vivo Model. Anticancer Res. 2016; 36(9):4595-4600.
[9] Khosrawipour V, Khosrawipour T, Diaz-Carballo D, et al. Exploring the spatial drug distribution pattern during Pressurized IntraPeritoneal Aerosol Chemotherapy (PIPAC). Ann SurgOncol. 2016; 23(4):1220-1224.

[10] Khosrawipour V, Mikolajczyk A, Schubert J, et al. Pressurized Intra-Peritoneal Aerosol Chemotherapy (PIPAC) via endoscopical microcatheter system. Anticancer Res Jun. 2018; 38(6):3447-3452.

[11] Dedrick RL, Myers CE, Bungay PM, et al. Pharmacokinetic rational for the peritoneal drug administration in the treatment of ovarian cancer. Cancer Treat Rep. 1978; 6:1-11

[12] Los G, Mutsaers PH, van der Vijgh WJ, et al. Direct diffusion of cis-diamminedichloroplatinum(II) in intraperitoneal rat tumor after intraperitoneal chemotherapy: a comparison with systemic chemotherapy. Cancer Res.1989; 49: 3380-3384.

[13] Jain RK. Barriers to drug delivery in solid tumors. Sci Am. 1994; 271:58-65

[14] Jacquet P, Sugarbaker PH. Peritoneal-plasma barrier. Cancer Treat Res. 1996; 82:53-63.

[15] Khosrawipour V, Khosrawipour T, Hedayat-Pour Y, et al. Effect of Whole abdominal Irradiation on penetration Depth of Doxorubicin in Normal Tissue after Pressurized Intraperitoneal Aerosol chemotherapy (PIPAC) in a Post-mortem Swine Model. Anticancer Res. 2017; 37(4): 1677-1680.

[16] Khosrawipour V, Khosrawipour T, Kern AJ, et al. Distribution pattern and penetration depth of doxorubicin after pressurized intraperitoneal aerosol chemotherapy (PIPAC) in a postmortem swine model. J Cancer Res ClinOncol. 2016; 142(11): 2275-2280.

[17] Khosrawipour T, Dan Wu, Bellendorf A, et al. Feasibility of Single Tumorspot treatment in Peritoneal Carcinomatosisi via Close range Doxorubicin impaction in Pressurized Intra-Peritoneal Aerosol Chemotherapy (PIPAC). J Clin Exp Oncol. 2017; 6(3).

[18] Khosrawipour T, Khosrawipour V and Giger-Pabst U. Pressurized intraperitoneal aerosol chemotherapy in patients suffering from peritoneal carcinomatosis of pancreatic adenocarcinoma. PLoS One. 2017; 19:12(10).

[19] Odendahl K, Solass W, Demtröder C, et al. Quality of life of patients with end-stage peritoneal metastasis treated with pressurized intraperitoneal Aerosolchemotherapy (PIPAC). Eur J SurgOncol. 2015; 41(10): 1379-1385.

[20] Facy O, Al Samman S, Magnin G, et al. High pressure enhances the effect of hyperthermia in intraperitoneal chemotherapy with oxaliplatin: an experimental study. Ann Surg.2012; 256(6):1084-8.

[21] Ceelen WP, Påhlman L, Mahteme H. Pharmacodynamic aspects of intraperitoneal cytotoxic therapy. Cancer Treat Res. 2007; 134:195-214.

[22] Arndt D, Zeisig R, Fichtner I, et al. Pharmacokinetics of sterically stabilized hexadecylphosphocholine liposomes versus conventionalliposomes and free hexacyclophosphocholine in tumor-free and human breascacinomabaering mice. Breastcancer research and threatment.1999; 58:71-80.

[23] Kresta A, Shek PN, Odumeru J, et al. Distribution of free and liposome-encapsuledcefoxitin in experimental intra-abdominal sepsis in rats. Journal of Pharmacy and Pharmacology.1993; 45: 779-783

[24] Rosa P and Clementi F. Absorption and tissue distribution of doxorubicin entrapped in liposomes following intravenous or intraperitoneal administration. Pharmacology. 1983; 26: 221-229

[25] Armstrong DK, Fleming GF, Markman M, et al. A phase I trial of intraperitoneal sustained release of paclitaxel microspheres (Paclimer) in recurrent ovarian cancer. A Gynecology Group study. Gynecologic Oncology. 2006; 103: 391-396

[26] Sugiyama T, Kumagai S, Nishida T, et al. Experimental and clinical evaluation of cisplatin-containing microsphere as intraperitoneal chemotherapy for ovarial cancer. Anticancer Research. 1998; 18: 2387-2842.

[27] Santos MA, Goertz DE und Hynynen K. Focused Ultrasound Hyperthermia Mediated Drug Delivery Using Thermosensitive Liposomes and Visualized With in vivo Two-Photon Microscopy. Theranostics. 2017; 7(10):2718-2731.

[28] Ping X, Angang D, Xia G, et al. Improved Efficacy of Liposomal Doxorubicin Treatment of Superficial Tumors by Thermotherapy. Technol Cancer Res Treat 2016; 15(2):314-21.

[29] Hirano K and Hunt CA. Lymphatic transport of liposome -encapsuled agents: Effect of liposome size following intraperitoneal administration. Journal of Pharmaceutical Sciences. 1985; 74: 915-921.

[30] Khosrawipour V, Diaz-Carballo D, Acikelli AH, et al. Cytotoxic effect of different treatment parameters in pressurized intraperitoneal aerosol chemotherapy (PIPAC) on in vitro proliferation of human colonic cancer cells. World J Surg Oncol. 2017; 15(1):94. 